\title{
Strain Differences in Lithium Attenuation of d-Amphetamine-Induced Hyperlocomotion: A Mouse Model for the Genetics of Clinical Response to Lithium
}

\author{
Todd D Gould*,', Kelley C O’Donnell', Alyssa M Picchini' ${ }^{1,2}$ and Husseini K Manji' \\ 'Laboratory of Molecular Pathophysiology, Mood and Anxiety Disorders Program, National Institute of Mental Health, NIH, HHS, Bethesda, \\ MD, USA
}

\begin{abstract}
Lithium attenuation of stimulant-induced hyperlocomotion is a rodent model that may be useful both to understand the mechanism of the therapeutic action of lithium and to develop novel lithium-mimetic compounds. To lay the foundation for future investigations into the neurobiology and genetics of lithium as a therapeutic agent, we studied the effect of lithium on d-amphetamine-induced hyperlocomotion in 12 (3 outbred) mouse strains. In our initial screening, mice received either (I) no drugs, (2) LiCl only, (3) damphetamine only, or (4) $d$-amphetamine and $\mathrm{LiCl}$. Whereas there was no significant effect of $\mathrm{LiCl}$ alone on locomotion in any strain, there was a large degree of strain variation in the effects of $\mathrm{LiCl}$ combined with $\mathrm{d}$-amphetamine. $\mathrm{LiCl}$ attenuated $\mathrm{d}$-amphetamine-induced hyperlocomotion in C57BL/6J, C57BL/6Tac, Black Swiss, and CBA/J mice, whereas CD-I, FVB/NJ, SWR/J, and NIH Swiss mice, which were responsive to $d$-amphetamine, showed no significant effect of $\mathrm{LiCl}$. d-Amphetamine-induced hyperlocomotion in the $\mathrm{C} 3 \mathrm{H} / \mathrm{HeJ}$ strain was increased by pretreatment with lithium. A subset of strains were treated for 4 weeks with lithium carbonate before the $d$ amphetamine challenge, and in each of these strains, lithium produced effects identical to those seen following acute administration. Strain responsiveness to lithium was not dependent upon the dose of either d-amphetamine or LiCl. Further, the results are not explained by brain lithium levels, which suggests that these behavioral responses to lithium are under the control of inherent genetic or other biological mechanisms specific to the effects of lithium on brain function.
\end{abstract}

Neuropsychopharmacology (2007) 32, I 32 I - 1333. doi: I0. I 038/sj.npp. I 30 I 254; published online 6 December 2006

Keywords: hyperactivity; endophenotype; bipolar disorder; stimulant; manic-depressive illness; depression

\section{INTRODUCTION}

Bipolar disorder is a severe neuropsychiatric disorder that affects at least $1 \%$ of the world's population when a strict definition (DSM IV bipolar I disorder) is applied, and up to $11 \%$ when using less strict criteria (Angst et al, 2003). Lithium is one of the primary treatments for bipolar disorder (Schou, 2001). However, in spite of the efficacy of lithium in many patients, adherence is often poor, owing to the side effects and narrow therapeutic window of the drug. Additionally, some patients never respond to lithium, and our ability to identify these patients a priori is modest at best.

*Correspondence: Dr TD Gould, Laboratory of Molecular Pathophysiology, Mood and Anxiety Disorders Program, National Institute of Mental Health, NIH, HHS, Bldg 35, Rm IC-9|2, 35 Convent Drive, Bethesda, MD 20892-37| I, USA, Tel: + | 30| 45 | 8435, Fax: + | 30 | 480 0123, E-mail: gouldt@mail.nih.gov

${ }^{2}$ Current address: Department of Pharmacology, Columbia College of Physicians and Surgeons, 630 West 168th Street, PH 7W 318, New York, NY 10032, USA.

Received 24 April 2006; revised 6 September 2006; accepted 2 October 2006
Current research is identifying and investigating novel direct targets and signaling pathways that may mediate many of the biochemical and behavioral effects of lithium. Indeed, although the initial molecular target of the drug has not been ascertained, some possible candidates do exist, including glycogen synthase kinase-3 (GSK-3) and inositol monophosphatases (Berridge et al, 1989; Gould et al, 2004b; Klein and Melton, 1996). These studies may ultimately lead to improved therapeutics; however, having appropriate models that have been extensively examined will also be useful for the identification of novel compounds that would ideally share the therapeutic target, but not the side effects, of lithium. In addition to their utility in screening for such lithium-mimetic compounds, animal models may assist in defining the genetics of lithium response, offering further insight into the fundamental pathology of bipolar disorder.

Behavioral models for bipolar disorder, or for the mechanism of action of mood-stabilizing medications, are not as well established as those for many other psychiatric diseases, including anxiety and depression (Einat et al, 2003). However, in the study of complex illnesses, focus is increasingly placed on the development of animal models 
that may be related to clinical endophenotypes (Gould and Gottesman, 2006). As inherent and quantifiable measures of brain function, endophenotypes can potentially be used to investigate the fundamental pathology of complex illnesses, the manifest symptoms of which often cannot be quantified (Gottesman and Gould, 2003). The use of dopaminergic stimulants has been associated with the onset of mania in bipolar patients and with manic-like symptoms in control subjects (Anand et al, 2000; Mamelak, 1978; Murphy et al, 1971; Peet and Peters, 1995). Some studies report that lithium can attenuate or prevent the behavioral and/or functional effects of dopaminergic drugs (Bell et al, 2005; Huey et al, 1981; Silverstone et al, 1998; van Kammen et al, 1985; Van Kammen and Murphy, 1975; Willson et al, 2005). These data have led to the suggestion that how the human brain responds to dopaminergic stimulants may be a clinical endophenotype of bipolar disorder (Hasler et al, 2006). Certain aspects of this endophenotype can be explored in animal models; for example, the mouse model of amphetamine-induced hyperlocomotion, although not an endophenotype itself, may provide a means of investigating the altered neurobiological response to amphetamine reported in clinical studies. In 1971, Cox et al (1971) reported that lithium attenuated stimulant-induced hyperlocomotion in rats. This effect was later reported in mice (Berggren et al, 1978; Borison et al, 1978). Because the administration of dopaminergic stimulants to rodents induces a characteristic increase in activity, and because this activity is attenuated by lithium administration, the hyperlocomotion model may provide insight into the clinical endophenotype described above. Thus, the potential value of the hyperlocomotion model is multifold: it can be used to explore the therapeutic action of lithium; it can be used in the development and testing of novel lithiummimetic compounds; it can help define the genes relevant to human response and nonresponse to lithium; and it can help to explore a potential clinical endophenotype.

Recent advances in neurobehavioral genetics have increased our awareness of the behavioral patterns of different mouse strains, and have characterized essential neural processes that are influenced by strain-dependent inheritable traits. Inbred and outbred mice are commonly utilized to compare effects of biological and genetic variations in behavioral models. These studies highlight the utility of studying strain differences to (1) elucidate the molecular, cellular, and genetic underpinnings of complex behaviors, (2) define predictive responses to current medications, (3) encourage the development of standardized procedures among laboratories, and (4) determine appropriate mouse strains for behavioral models and for transgenic backgrounds.

We have undertaken a comparison of inbred and outbred mouse strains to delineate the range of behavioral effects of lithium administration before the induction of hyperlocomotion by $d$-amphetamine. We chose $d$-amphetamine because this stimulant has frequently been used in both rodent and human studies of the effects of lithium. Twelve (3 outbred) mouse strains (Black Swiss, CD-1, NIH Swiss, 129S6/SvEv, A/J, C3H/HeJ, C57BL/6J, C57BL/6Tac, CBA/J, $\mathrm{DBA} / 2 \mathrm{~J}, \mathrm{FVB} / \mathrm{NJ}, \mathrm{SWR} / \mathrm{J}$ ) received either (1) no drugs, (2) lithium only, (3) $d$-amphetamine only, or (4) $d$-amphetamine and lithium. We have characterized both lithium- responsive and -unresponsive strains. In a subset of strains we show that the strain-dependent effects seen with acute administration are maintained after long-term lithium administration, and that the results are due neither to strain differences in brain penetration of lithium nor to the dose of $d$-amphetamine. These results will allow for biological and genetic studies to determine the molecular and cellular underpinnings of the strain-dependent behavioral differences in this model. They are a step toward understanding lithium-responsive and -unresponsive subtypes of bipolar disorder patients, and toward a more comprehensive definition of the actions of this mood stabilizer.

\section{METHODS}

\section{Mice}

Male mice were obtained from outside breeding colonies. A/J, C3H/HeJ, C57BL/6J, CBA/J, DBA/2J, FVB/NJ, SWR/J (The Jackson Laboratories, Bar Harbor, Maine), C57BL/ 6Tac, 129S6/SvEv, and Black Swiss (Taconic, Germantown, NY), CD-1 (Charles River Laboratories Inc., Wilmington, Massachusetts), and NIH Swiss (Harlan, Indianapolis, Indiana) were transported to our laboratory, where experimentation started no less than 1 week later, to allow for appropriate acclimatization time. Mice were housed four per cage in an animal room with constant temperature $\left(22 \pm 1^{\circ} \mathrm{C}\right)$ and a 12-h light/dark cycle (lights on/off at 0600/ 1800 ), with free access to food and water. All experimental procedures were approved by the National Institute of Mental Health Animal Care and Use Committee (Protocol: LMP-02-05), and were conducted in full accordance with the Guide for the Care and Use of Laboratory Animals.

\section{Drugs}

Experiments were performed in the light phase under dimmed halogen lights ( $\sim 35$ lux $)$. At 8-9 weeks of age, mice were weighed and randomly selected to receive either (1) no drugs, (2) lithium only, (3) $d$-amphetamine only, or (4) lithium and $d$-amphetamine. Mice were given (i.p.) either lithium chloride (LiCl, Sigma, Saint Louis, Missouri) dissolved in $0.9 \%$ saline, or saline alone. Fifteen minutes later, mice received (i.p.) either $d$-amphetamine (Sigma, Saint Louis, Missouri) dissolved in saline, or saline alone. For the long-term experiments, at 8 weeks of age mice were randomly selected to receive either control chow or lithium carbonate chow. Rodent chow was custom-produced by Bio-Serve (Frenchtown, New Jersey). Chows containing lithium carbonate were identical to the control chow with the exception of the added drug, and were produced at both a 'low' and a 'normal' concentration (1.2 and $2.4 \mathrm{~g} / \mathrm{kg}$ lithium carbonate). The dose of lithium carbonate is that previously used by our group in both rats and mice to achieve serum levels within the therapeutic range seen in humans (Gould et al, 2004a, 2003). Mice received low-dose chow for 1 week, followed by high-dose chow for 3 weeks.

\section{Activity Monitoring and Data Analysis}

Immediately after amphetamine administration, individual mice were placed in the center of $35 \times 35 \times 35 \mathrm{~cm}$ Plexiglas 
arenas, where their location was recorded by the Ethovision videotracking system (Noldus, Wageningen, The Netherlands). The Ethovision system follows the center of the body of the mouse and records its position according to the location of this point. Data analysis was performed by Ethovision software, and distances moved within each 5-min interval were calculated and plotted. Total distance moved was computed for the time frame from 30 to 90 min following the beginning of data acquisition. We did not begin this analysis at time zero in order to eliminate effects of acclimation to a novel environment, the delayed effects of $d$ amphetamine in certain strains, and possible acute nonspecific toxic effects of LiCl. Analysis of total distance moved did not extend past 90 min because in many strains the locomotor effects of $d$-amphetamine begin to disappear after this time.

\section{Lithium Concentration Assay}

Following the experiment, mice were returned to their home cages. On a separate day at least 1 week following the behavioral experiments, 6 mice were again weighed and randomly selected to receive $100 \mathrm{mg} / \mathrm{kg} \mathrm{LiCl}$ dissolved in saline. The rodent brain is completely depleted of measurable lithium 2 days after administration, leaving no lithium from the previous experiment in the brain (unpublished data; Morrison et al, 1971; Mukherjee et al, 1976). Forty-five minutes later, mice were killed by decapitation, and their intact brains were rapidly dissected and stored at $-80^{\circ} \mathrm{C}$. Following long-term lithium carbonate administration, a subgroup of the mice were selected for brain dissection, and at the same time blood was removed, by cardiac puncture, from the remaining lithium carbonate-treated mice. To determine serum lithium levels ( $\mathrm{mmol} / \mathrm{l})$, serum was isolated from whole blood by centrifugation. Brain lithium levels ( $\mathrm{mmol} / \mathrm{kg}$ wet weight) were determined following polytron homogenization of the entire brain (Kinematica AG Model PCU 11, Littau, Switzerland) in 3 volumes of $0.5 \mathrm{~N}$ trichloroacetic acid, followed by centrifugation (Hamburger-Bar et al, 1986). Lithium assays were performed with a digital flame photometer (Cole-Palmer Model 2655-00, Chicago, Illinois).

\section{Statistics}

Statistical analysis was performed by SPSS 11 for Macintosh and Graphpad Prism Version 4. Statistical analysis utilized either one- or two-way ANOVA. A Dunnett's post hoc test was used to compare significant results in dose-response experiments. Tukey's post hoc test was used to compare all other results. Pearson's correlation (two-tailed) was utilized to analyze the effects of brain lithium concentration on attenuation of $d$-amphetamine hyperlocomotion. Data are reported as mean \pm SE. $p<0.05$ was considered significant.

\section{RESULTS}

\section{Experiment 1: LiCl Dose Response in C57BL/6J Mice}

We first investigated the effects of $\mathrm{LiCl}$ administered at different doses $(0,50,100$, and $200 \mathrm{mg} / \mathrm{kg}) 15 \mathrm{~min}$ before administration of $2 \mathrm{mg} / \mathrm{kg} d$-amphetamine in the common C57BL/6J strain. Immediately following administration of $d$-amphetamine, mice were placed in the center of the arena.
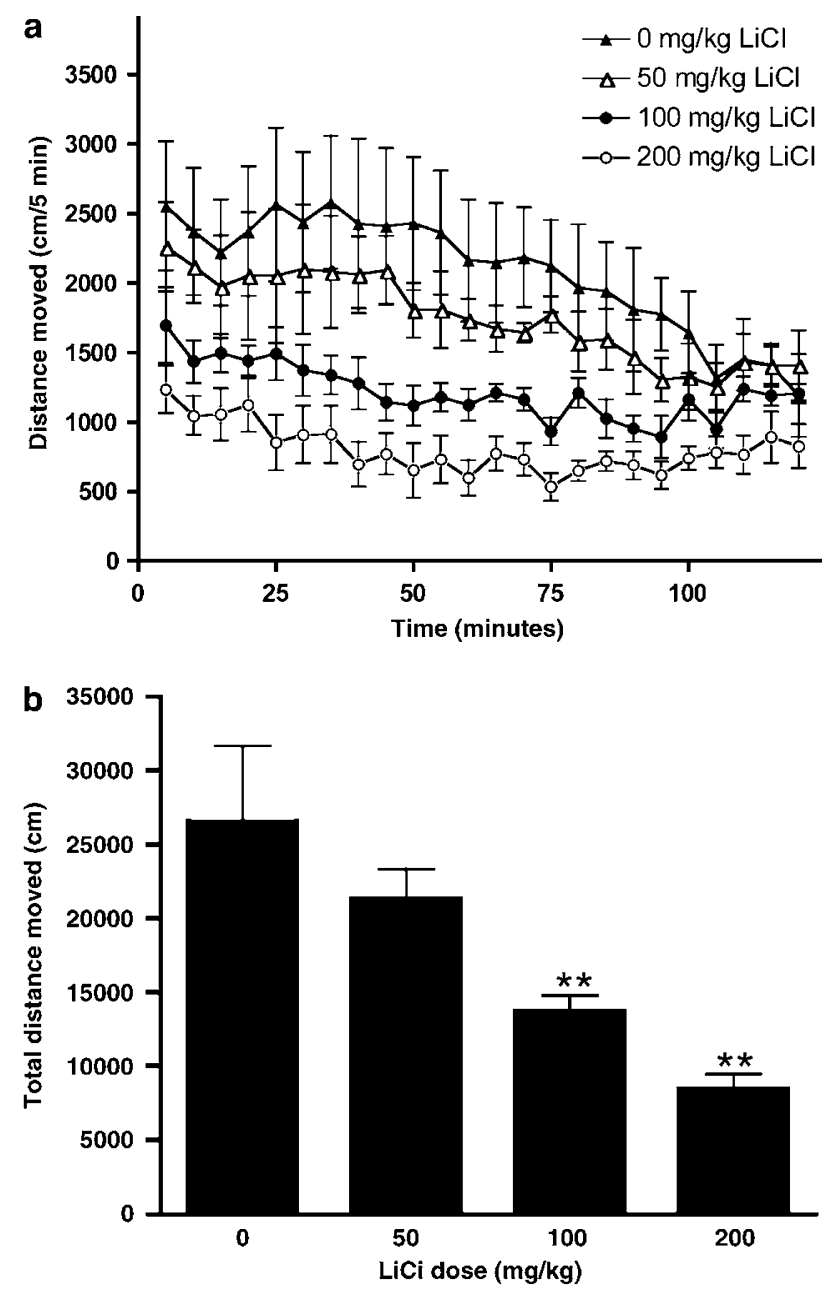

Figure I LiCl dose-response curve in C57BL/6) mice given $2 \mathrm{mg} / \mathrm{kg} d$ amphetamine. $\mathrm{LiCl}$ was administered i.p. at various doses $15 \mathrm{~min}$ before $2 \mathrm{mg} / \mathrm{kg} \mathrm{d}$-amphetamine. (a) Distance moved $(\mathrm{cm})$ during 5-min intervals. (b) Total distance moved $(\mathrm{cm})$ during 30-90 min. $* * 0<0.01$ compared with vehicle-treated mice, Dunnett's post hoc test (5-6 mice per group).

Activity graphs revealed that an increase in $\mathrm{LiCl}$ dose resulted in a decrease in $d$-amphetamine-induced hyperlocomotion (Figure 1a). One-way ANOVA revealed an overall significant effect of $\mathrm{LiCl}$ dose on total distance moved, $\mathrm{F}(3,19)=9.56, p<0.001$ (Figure 1b). Dunnett's post hoc test revealed that doses of 100 and $200 \mathrm{mg} / \mathrm{kg}$ significantly inhibited $d$-amphetamine-induced hyperlocomotion compared to vehicle alone $(p<0.01)$. In studies of baseline activity (no $d$-amphetamine), there was no significant effect of $\mathrm{LiCl}$ to decrease locomotion at any of these doses; however, a trend was observed at $200 \mathrm{mg} / \mathrm{kg}$ (data not shown). As $100 \mathrm{mg} / \mathrm{kg} \mathrm{LiCl}$ resulted in significant attenuation of $d$-amphetamine-induced hyperlocomotion in C57BL/6J mice, with no indication of inhibition of baseline activity, we decided to use this dose in subsequent experiments.

Experiment 2: Effects of Acute $\mathrm{LiCl}$ on $d$-Amphetamine-Induced Hyperlocomotion in Outbred Mice

Three common outbred strains, Black Swiss, CD-1, and NIH Swiss, were chosen to study variations in the modulation of 

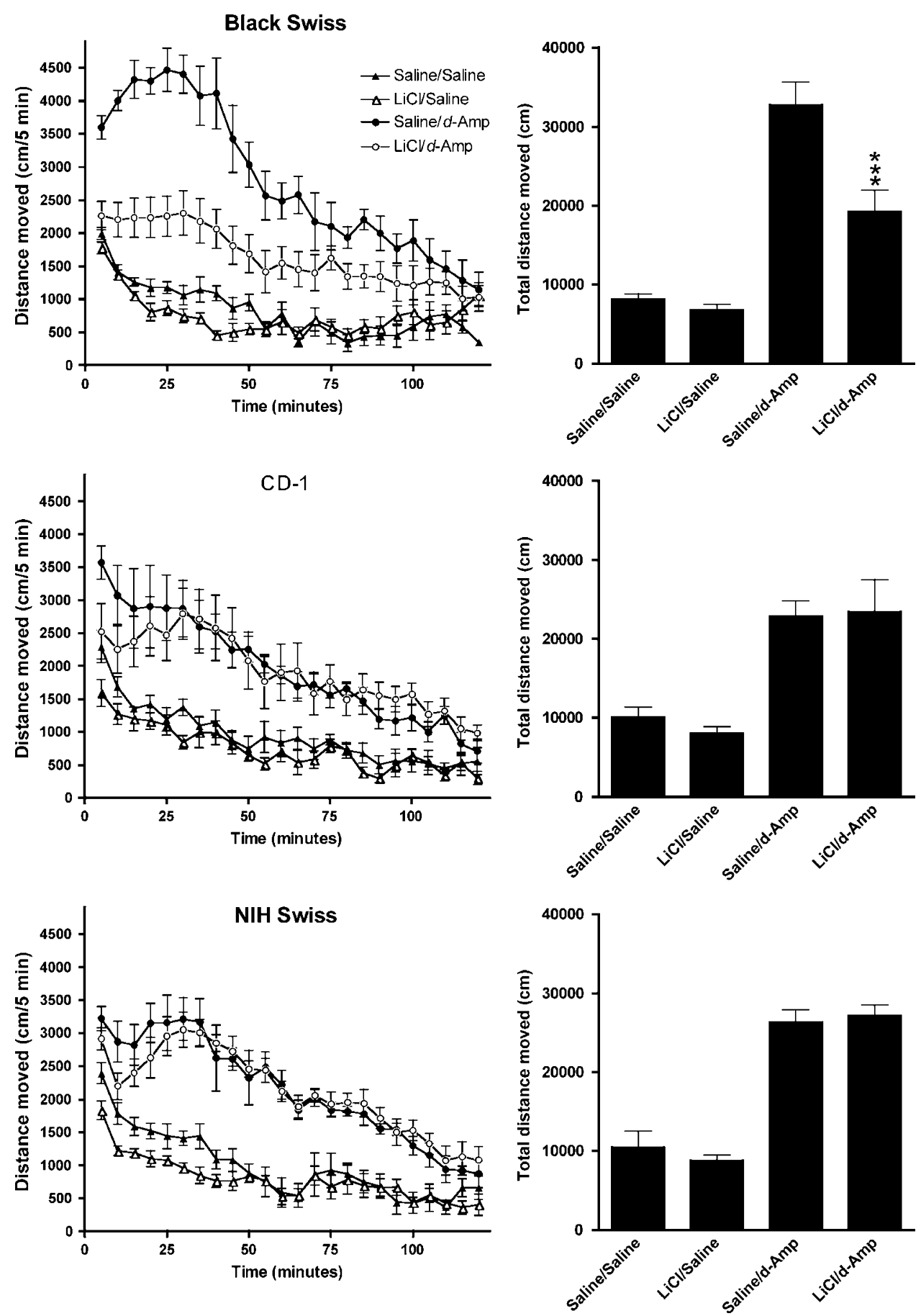

Figure 2 Locomotor activity curves and total distanced moved for outbred mouse strains. Mice received either (I) no drugs (Saline/Saline), (2) LiCl only (LiCl/Saline), (3) d-amphetamine only (Saline/d-Amp), or (4) LiCl and d-amphetamine ( $\mathrm{LiCl} / \mathrm{d}$-Amp). The graphs on the left detail distance moved (cm) during 5-min intervals. The graphs on the right show total distance moved in centimeters during the 30-90 min period for the same group of mice shown on the left. Two-way ANOVA revealed that $d$-amphetamine increased locomotion in all outbred strains. See Table I for statistical analysis. $* * * * *<0.00$ I comparing $d$-amphetamine and $\mathrm{LiCl} / d$-amphetamine groups, Tukey post hoc test ( 6 mice per group).

$d$-amphetamine-induced hyperlocomotion in the mouse. Activity graphs suggested strain differences in the effect of LiCl to attenuate $d$-amphetamine locomotion (Figure 2). This was confirmed by statistical analysis of total distance moved (Figure 2). There was a significant main effect of $d$ amphetamine in all outbred strains (Table 1). There was a significant effect of $\mathrm{LiCl}$ and a significant interaction between $d$-amphetamine and LiCl, only in Black Swiss mice
(Table 1). A Tukey post hoc test was utilized within each strain to compare saline/saline- with $\mathrm{LiCl} /$ saline-treated mice, and saline/d-amphetamine- with $\mathrm{LiCl} / d$-amphetamine-treated mice (our primary outcomes of interest). $\mathrm{LiCl}$ alone had no significant effect on locomotion in any outbred strain that we studied. $\mathrm{LiCl}$ had a significant effect on $d$-amphetamine-induced hyperlocomotion in Black Swiss mice, and no significant effect on the other two 
Table I Statistical Analysis of Total Distance Moved for Outbred and Inbred Strains

\begin{tabular}{|c|c|c|c|c|c|c|}
\hline & df & $\mathbf{A}$ & Li & $\mathbf{A} \times \mathbf{L i}$ & $\begin{array}{c}\text { S/S vs Li/S } \\
\mathbf{p}=\end{array}$ & $\begin{array}{c}\text { S/A vs Li/A } \\
p=\end{array}$ \\
\hline Black Swiss & $(1,20)$ & $F=79.52, p<0.001$ & $F=12.7 \mid, p=0.002$ & $F=8.54, p=0.008$ & NS & 0.001 \\
\hline CD-I & $(I, 20)$ & $\mathrm{F}=33.84, p<0.00 \mathrm{I}$ & $F=0.087, p=0.77$ & $F=0.31, p=0.58$ & NS & NS \\
\hline $\mathrm{NIH}$ Swiss & $(1,20)$ & $F=|24.95, p<0.00|$ & $F=0.96, p=0.76$ & $F=0.69, p=0.42$ & NS & NS \\
\hline \multicolumn{7}{|l|}{ Inbred strains } \\
\hline I29S6/SvEv & $(1,20)$ & $F=|5.23, p=0.00|$ & $F=0.30, p=0.59$ & $F=0.75, p=0.40$ & NS & NS \\
\hline$A / J$ & $(I, 20)$ & $F=0.53, p=0.82$ & $F=0.19, p=0.67$ & $F=1.07, p=0.31$ & NS & NS \\
\hline $\mathrm{C} 3 \mathrm{H} / \mathrm{HeJ}$ & $(1,20)$ & $\mathrm{F}=60.95, p<0.00 \mathrm{I}$ & $F=9.58, p=0.006$ & $F=3.06, p=0.095$ & NS & 0.013 \\
\hline C57BL/6] & $(1,20)$ & $\mathrm{F}=50.72, p<0.00 \mathrm{I}$ & $F=12.24, p=0.002$ & $F=|8.00, p<0.00|$ & NS & 0.000 \\
\hline SWR/J & $(1,20)$ & $F=|54.48, p<0.00|$ & $F=0.82, p=0.38$ & $F=0.78, p=0.39$ & NS & NS \\
\hline
\end{tabular}

The table reports results of two-way ANOVA within each strain: A, overall effect of $\mathrm{d}$-amphetamine; Li, overall effect of LiCl; A $\times$ Li, interaction between $\mathrm{d}$ amphetamine and $\mathrm{LiCl}$. A Tukey post hoc test was performed incorporating all groups in the analysis; the primary outcome measures of saline/saline- (S/S) and LiCl/ saline- (Li/S) treated mice and between saline/d-amphetamine- (S/A) and LiCl/d-amphetamine- (Li/A) treated mice are reported within each strain. NS: nonsignificant.

outbred strains (Figure 2; Table 1). We did not perform statistical comparisons between strains because the experiments were performed on separate days.

\section{Experiment 3: Effects of Acute $\mathrm{LiCl}$ on $d$-Amphetamine-Induced Hyperlocomotion in Inbred MICE}

Nine inbred strains (129S6/SvEv, A/J, C3H/HeJ, C57BL/6J, C57BL/6Tac, $\mathrm{CBA} / \mathrm{J}, \mathrm{DBA} / 2 \mathrm{~J}, \mathrm{FVB} / \mathrm{NJ}$, and $\mathrm{SWR} / \mathrm{J}$ ) were selected owing to their common use in behavioral, transgenic, and biochemical experiments, in addition to their lineage relationship to the outbred strains tested. Activity graphs suggested strain differences in the effects of $\mathrm{LiCl}$ to attenuate $d$-amphetamine locomotion (Figure 3). This was confirmed by statistical analysis of total distance moved (Figure 4). There was a significant main effect of $d$ amphetamine in all inbred strains, with the exception of $\mathrm{A} / \mathrm{J}$ (Table 1). The lack of effect of $d$-amphetamine in $\mathrm{A} / \mathrm{J}$ mice is consistent with the published literature (Anisman et al, 1975; Kitahama and Valatx, 1979). LiCl had a significant main effect in $\mathrm{C} 3 \mathrm{H} / \mathrm{HeJ}$, C57BL/6J, C57BL/6Tac, and CBA/J strains (Table 1). There was a significant interaction between $\mathrm{LiCl}$ and $d$-amphetamine in C57BL/6J, C57BL/ $6 \mathrm{Tac}$, and $\mathrm{CBA} / \mathrm{J}$ strains of mice (Table 1). As with the outbred mouse strains, a Tukey post hoc test was used to compare saline/saline- with $\mathrm{LiCl} /$ saline-treated mice, and saline/d-amphetamine- with $\mathrm{LiCl} / d$-amphetamine-treated mice within each strain. $\mathrm{LiCl}$ alone had no significant effect on locomotion in any inbred strain that we studied. $\mathrm{LiCl}$ had a significant effect of decreasing $d$-amphetamineinduced hyperlocomotion in C57BL/6J, C57BL/6Tac, and $\mathrm{CBA} / \mathrm{J}$ strains. $\mathrm{LiCl}$ had a significant effect of increasing $d$-amphetamine-induced hyperlocomotion in the $\mathrm{C} 3 \mathrm{H} / \mathrm{HeJ}$ strain (Table 1). We did not perform statistical comparisons between strains because the experiments were performed on separate days.

\section{Experiment 4: Determination of Brain Lithium Levels}

We wanted to be certain that the various strain effects of $\mathrm{LiCl}$ were not due to brain availability of the drug. Therefore, on a separate day at least 1 week following the behavioral experiments, 6 mice from each strain were randomly selected to receive $100 \mathrm{mg} / \mathrm{kg} \mathrm{LiCl}$. Mice were killed 45 min following administration of LiCl; whole brains were dissected and immediately frozen until lithium extraction and flame photometric analysis. Pilot experiments found, similar to the reported literature in rats, that brain lithium levels were $1 / 3-1 / 2$ that found in serum 45 min following administration (data not shown; Ghoshdastidar et al, 1989; Morrison et al, 1971). Table 2 reports mean whole-brain lithium concentration in all 12 strains. One-way ANOVA revealed an overall effect of strain on brain lithium levels, $\mathrm{F}(11,59)=4.98, p<0.001$. A Tukey post hoc test revealed significant differences in brain lithium concentration between $129 \mathrm{~S} 6 / \mathrm{SvEv}$ and $\mathrm{C} 3 \mathrm{H} / \mathrm{HeJ}(p<0.05)$, $\mathrm{CBA} / \mathrm{J}(p<0.05), \mathrm{A} / \mathrm{J}(p<0.001)$, and $\mathrm{DBA} / 2 \mathrm{~J}(p<0.001)$ strains, and between DBA/2J and Black Swiss $(p<0.01)$ and NIH Swiss $(p<0.01)$ strains. To determine if strain differences in the effects on $d$-amphetamine-induced hyperlocomotion were due to brain lithium availability, we correlated brain lithium concentration in each strain with the percent change in activity of the differences between the baseline levels: $(1-$ (mean lithium/d-amphetaminemean lithium/saline)/(mean saline/d-amphetaminemean saline/saline $) \times 100$. These data are plotted in Figure 5 (the $d$-amphetamine-unresponsive strain $\mathrm{A} / \mathrm{J}$ was excluded from the plot and subsequent correlation analysis). There was no significant correlation between brain 

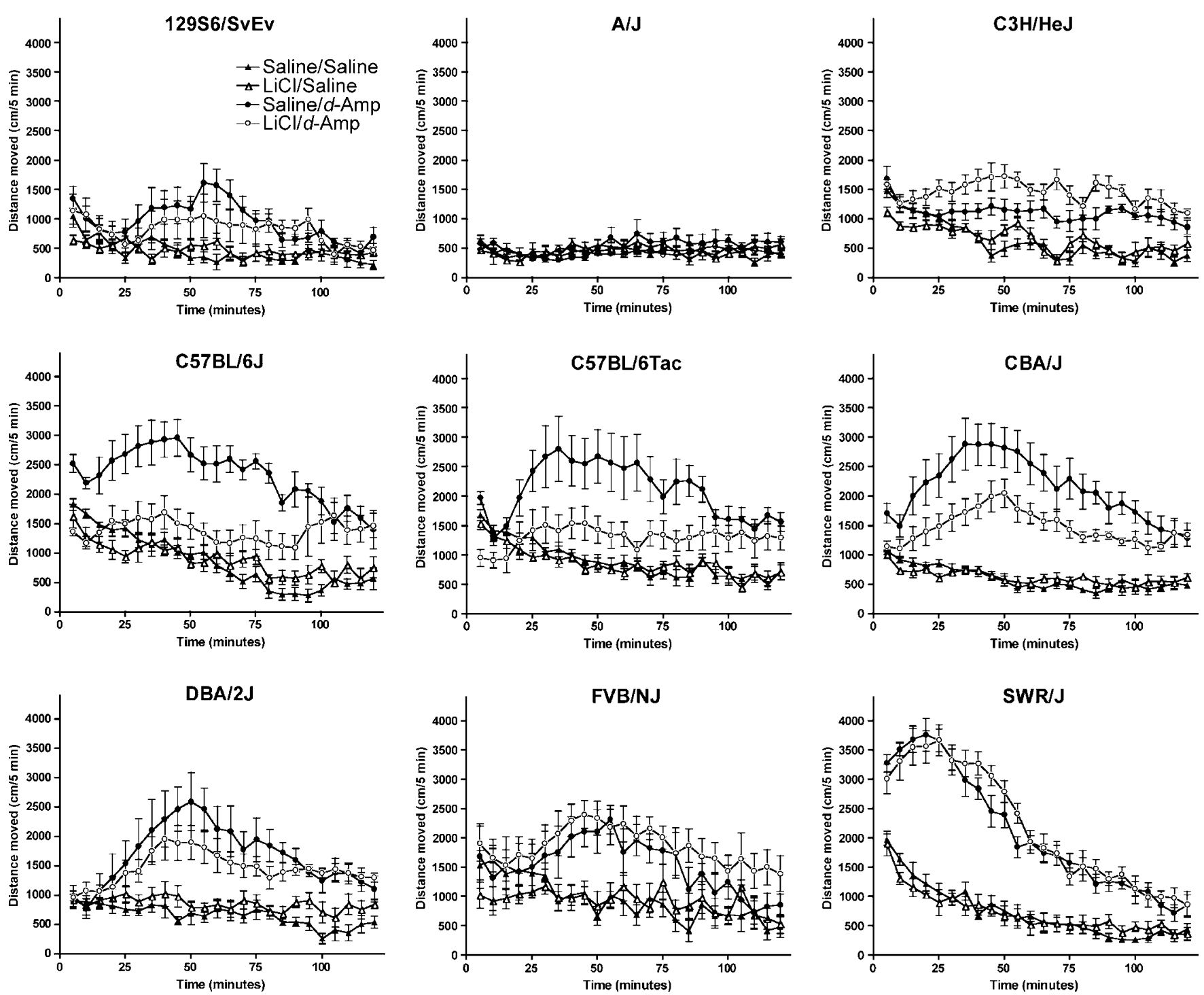

Figure 3 Locomotor activity curves for inbred strains. Mice received either (I) no drugs (Saline/Saline), (2) LiCl only (LiCl/Saline), (3) d-amphetamine only (Saline/d-Amp), or (4) LiCl and d-amphetamine ( $\mathrm{LiCl} / \mathrm{d}$-Amp). The graphs detail distance (cm) moved during 5 min intervals (6 mice per group). Top: Black Swiss; middle: CD-I; bottom: NIH Swiss.

lithium concentration and change in activity $(n=11$; Pearson's $r=-0.66, p=0.85$, two-tailed). Therefore, we concluded that strain differences in the actions of $\mathrm{LiCl}$ to decrease $d$-amphetamine-induced hyperlocomotion were not related to brain lithium levels.

\section{Experiment 5: Effects of $4 \mathrm{mg} / \mathrm{kg} d$-Amphetamine and LiCl Dose in C57BL/6J and FVB/NJ Mouse Strains}

Among the $\mathrm{LiCl}$ non-responsive strains, we selected the commonly available $\mathrm{FVB} / \mathrm{NJ}$ strain for dose-response studies. Similar to Experiment 1 with C57BL/6J mice (Figure 1), we administered $\mathrm{LiCl}$ at different doses $(0,50$, 100 , and $200 \mathrm{mg} / \mathrm{kg}$ ) $15 \mathrm{~min}$ before $2 \mathrm{mg} / \mathrm{kg} d$-amphetamine. Activity graphs suggested that no dose of $\mathrm{LiCl}$ attenuated $d$-amphetamine-induced hyperlocomotion in FVB/NJ mice (Figure 6). A higher dose of $\mathrm{LiCl}$ was not used because experiments showed that a dose of $300 \mathrm{mg} / \mathrm{kg}$ resulted in lethargy and gastrointestinal toxicity, as evidenced by a robust decrease in basal activity levels and severe diarrhea (data not shown). This was supported by statistical analysis, where one-way ANOVA revealed no significant effect of $\mathrm{LiCl}$ dose on total distance moved, $\mathrm{F}(3,20)=0.71, p=\mathrm{NS}$ (Figure 6). To determine if the results observed could be due to variations in the response of these strains to the dose of $d$-amphetamine, we administered $\mathrm{LiCl}$ (at different doses) in both $\mathrm{C} 57 \mathrm{BL} / 6 \mathrm{~J}$ mice and $\mathrm{FVB} / \mathrm{NJ}$ mice before administration of $4 \mathrm{mg} / \mathrm{kg} d$-amphetamine. A dose of $4 \mathrm{mg} /$ $\mathrm{kg} d$-amphetamine was chosen because at higher doses stereotyped behaviors compete with locomotor activity in both strains (unpublished data). Similar to Experiment 1, activity graphs illustrate that an increase in $\mathrm{LiCl}$ dose resulted in a decrease in $d$-amphetamine-induced hyperlocomotion in C57BL/6J mice (Figure 6). One-way ANOVA revealed an overall significant effect of $\mathrm{LiCl}$ dose on total distance moved, $\mathrm{F}(3,20)=5.17, p=0.0083$ (Figure 6). Dunnett's post hoc test revealed that doses of $150 \mathrm{mg} / \mathrm{kg}$ and $200 \mathrm{mg} / \mathrm{kg}$ significantly inhibited $d$-amphetamine-induced 


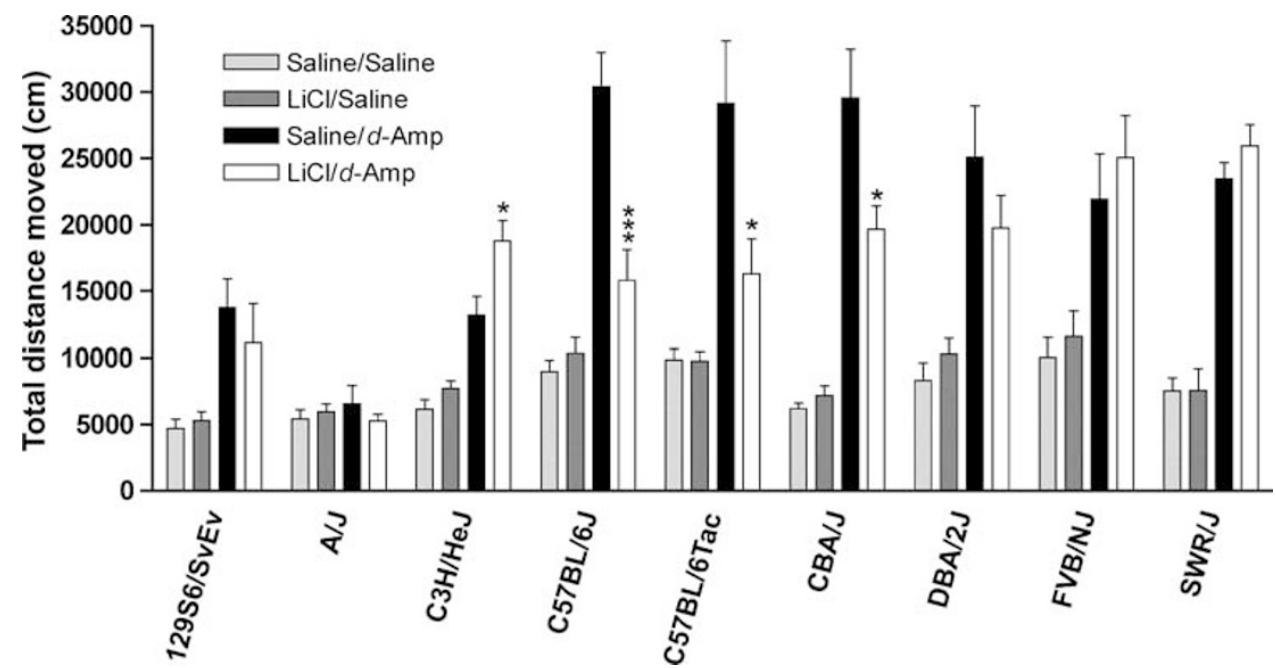

Figure 4 Total distance moved for inbred strains. Total distance moved in centimeters during 30-90 min for inbred mouse strains. Groups are no drugs (Saline/Saline), LiCl only (LiCl/Saline), d-amphetamine only (Saline/d-Amp), or LiCl and d-amphetamine (LiCl/d-Amp). Two-way ANOVA revealed that damphetamine increased locomotion in all inbred strains with the exception of A/J, which have previously been reported to be non-responsive to the effects of the compound to increase locomotion (Anisman et al, 1975; Kitahama and Valatx, 1979). See Table I for statistical analysis. * $p<0.05$; **** $p<0.00$ I comparing d-amphetamine and LiCl/d-amphetamine groups, Tukey post hoc test (6 mice per group).

Table 2 Lithium Concentration in the Brains of 12 Mouse Strains 45 min Following Administration of LiCl

\begin{tabular}{lc}
\hline Strain & Whole brain $[\mathrm{Li}] \mathbf{~ m m o l} / \mathbf{k g}$ wet weight \pm SE \\
\hline Black Swiss & $0.32 \pm 0.01$ \\
CD-I & $0.38 \pm 0.03$ \\
NIH Swiss & $0.31 \pm 0.01$ \\
I29S6/SvEv & $0.26 \pm 0.03$ \\
A/J & $0.43 \pm 0.02$ \\
C3H/HeJ & $0.39 \pm 0.01$ \\
C57BL6J & $0.38 \pm 0.02$ \\
C57BL/6Tac & $0.37 \pm 0.01$ \\
CBA/J & $0.39 \pm 0.01$ \\
DBA/2J & $0.47 \pm 0.01$ \\
FVB/NJ & $0.35 \pm 0.05$ \\
SWR/J & $0.35 \pm 0.04$ \\
\hline
\end{tabular}

hyperlocomotion compared to vehicle alone. However, $\mathrm{LiCl}$ did not appear to attenuate hyperlocomotion in $\mathrm{FVB} / \mathrm{NJ}$ mice at any of the three doses (Figure 6). This is supported by statistical analysis of total distance moved, which found no significant effect of $\mathrm{LiCl}$ dose, $\mathrm{F}(3,20)=0.26, p=\mathrm{NS}$ (Figure 6). Using an identical procedure to Experiment 4, we also obtained brain lithium levels in C57BL/6J and FVB/ $\mathrm{NJ}$ mice following administration of $200 \mathrm{mg} / \mathrm{kg} d$-amphetamine. The brain levels were significantly higher in FVB/NJ mice, confirming that the behavioral responses observed were not due to brain availability of lithium (C57BL/6J, $0.53 \pm 0.055 ; \mathrm{FVB} / \mathrm{NJ}, 0.81 \pm 0.025 ; t(6)=4.62, p=0.0036$ ). Overall, these results suggest that strain differences in $\mathrm{LiCl}$ attenuation of $d$-amphetamine-induced hyperlocomotion are due neither to the dose of $\mathrm{LiCl}$, nor to the dose of $d$-amphetamine.

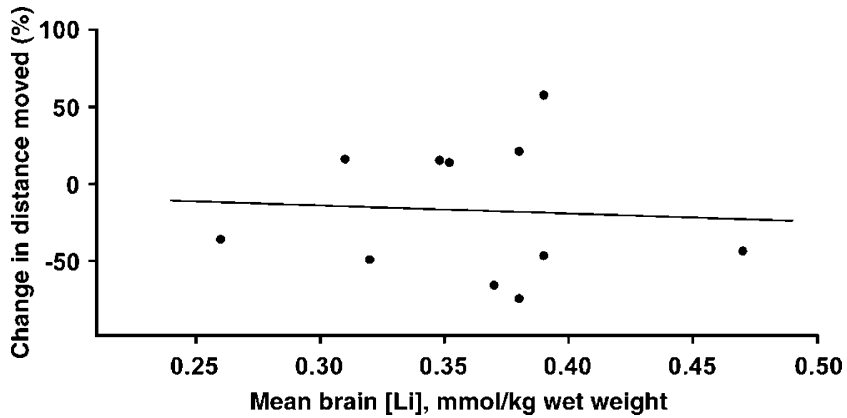

Figure 5 The effects of $\mathrm{LiCl}$ on d-amphetamine-induced hyperlocomotion vs brain lithium concentration in the mouse brain. $X$-axis: Mean brain lithium levels for each strain. $Y$-axis: Percent change in $d$-amphetamineinduced hyperlocomotion following administration of $\mathrm{LiCl}$ (see text for calculations). The $d$-amphetamine-unresponsive strain A/J was excluded from the plot and statistics. The line represents a fitted regression line for the values. There was no significant correlation between brain lithium concentration and change in activity $(n=11$; Pearson's $r=-0.66, p=0.85$, two-tailed).

\section{Experiment 6: Effects of 4-Week Lithium Carbonate Administration on $d$-Amphetamine Hyperlocomotion}

As patients who respond to lithium are generally maintained on long-term treatment, we chose a subset of strains with which to investigate whether the effects of $\mathrm{LiCl}$ seen after acute administration were observed after several weeks of lithium carbonate administration. We chose lithium carbonate rather than $\mathrm{LiCl}$ because our laboratory has extensive experience with using the carbonate form in rodent chow (Gould et al, 2004a, 2003). Included in this study was one strain in which $\mathrm{LiCl}$ reduced $d$-amphetamineinduced hyperlocomotion (C57/BL6J), another strain in which $\mathrm{LiCl}$ had no effect on $d$-amphetamine-induced hyperlocomotion $(\mathrm{FVB} / \mathrm{NJ})$, and one in which administration of LiCl increased $d$-amphetamine-induced hyperloco- 

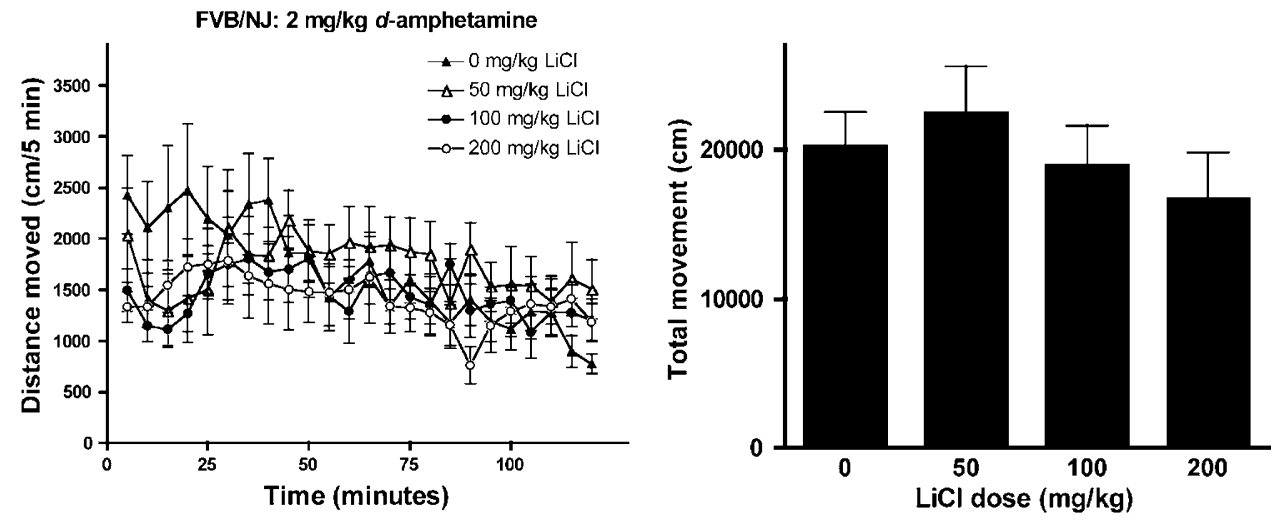

C57BL/6J: $4 \mathrm{mg} / \mathrm{kg}$ d-amphetamine
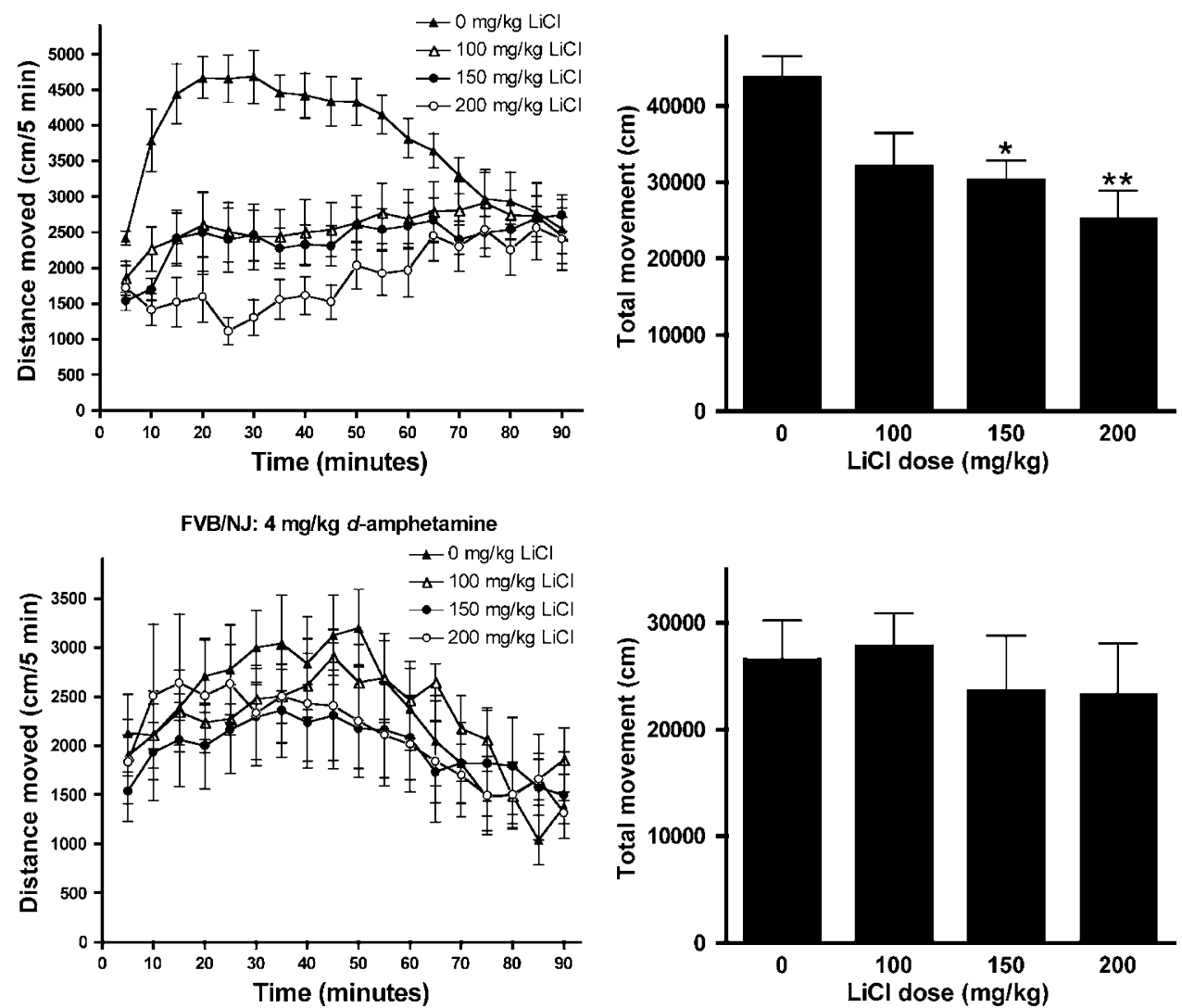

Figure 6 Effects of $4 \mathrm{mg} / \mathrm{kg}$ d-amphetamine and LiCl dose in C57BL/6) and FVB/NJ mouse strains. Mice received LiCl i.p. at various doses before either 2 or $4 \mathrm{mg} / \mathrm{kg} d$-amphetamine. Graphs on the left show distance moved $(\mathrm{cm})$ during 5-min intervals. Graphs on the right show total distance moved $(\mathrm{cm})$ during 30-90 min for the same group of mice shown on the left. Top: LiCl administered before $2 \mathrm{mg} / \mathrm{kg} \mathrm{d}$-amphetamine in FVB/NJ mice. Middle: LiC administered before $4 \mathrm{mg} / \mathrm{kg}$ in C57BL/6) mice. Bottom: LiCl administered before $4 \mathrm{mg} / \mathrm{kg}$ in FVB/NJ mice. * $p<0.05$, ** $p<0.0$ l compared with vehicletreated mice, Dunnett's post hoc test (6 mice per group).

motion $(\mathrm{C} 3 \mathrm{H} / \mathrm{HeJ})$. At 8 weeks of age, mice were randomly selected to receive either control chow or lithium carbonate chow. To parallel clinical procedure and to help prevent potential side effects, mice received low-dose chow $(1.2 \mathrm{~g} / \mathrm{kg}$ lithium carbonate) for 1 week, followed by regular dose chow $(2.4 \mathrm{~g} / \mathrm{kg}$ lithium carbonate) for 3 weeks. Controltreated mice received chow produced in an identical manner except for the addition of lithium carbonate. There was no significant difference in weight between control and lithium carbonate-treated mice, although a very strong trend was observed in the $\mathrm{C} 3 \mathrm{H} / \mathrm{HeJ}$ mice $(p=0.0501)$ (C57BL/6J: control, $28.4 \pm 0.7 \mathrm{~g}$; lithium carbonate, $26.6 \pm$
$0.9 \mathrm{~g} ; \mathrm{C} 3 \mathrm{H} / \mathrm{HeJ}$ : control, $26.3 \pm 0.5 \mathrm{~g} ;$ lithium carbonate $24.7 \pm 0.7 \mathrm{~g} ; \mathrm{FVB} / \mathrm{NJ}$ : control, $28.1 \pm 0.5 \mathrm{~g}$; lithium carbonate, $28.9 \pm 0.4 \mathrm{~g} ; 12$ mice per group). There was no significant difference in serum lithium levels between these 3 strains, and all values were within the human therapeutic concentration of the drug $(0.5-1.2 \mathrm{mM}), \mathrm{F}(2,15)=1.83, p=\mathrm{NS}$ (Figure 7a). One-way ANOVA revealed a significant difference in brain lithium levels between these 3 strains, $\mathrm{F}(2,15)=8.88, p=0.003$ (Figure $7 \mathrm{~b}$ ). Post hoc analysis (Tukey) found that brain lithium levels were significantly higher in $\mathrm{C} 3 \mathrm{H} / \mathrm{HeJ}$ mice compared to both $\mathrm{C} 57 \mathrm{BL} / 6 \mathrm{~J}$ $(p<0.01)$ and $\mathrm{FVB} / \mathrm{NJ}(p<0.05)$ mice. 
a

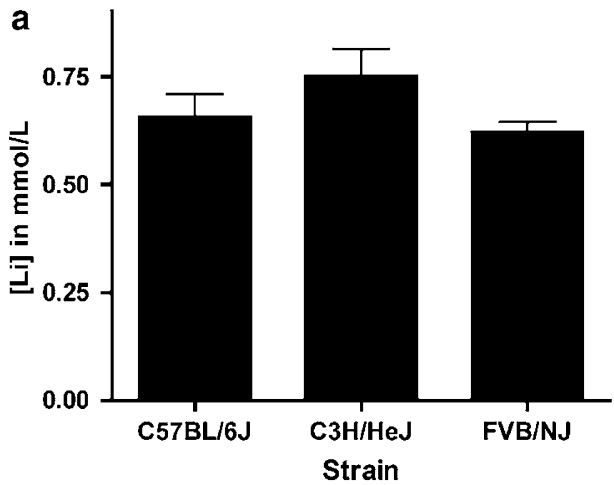

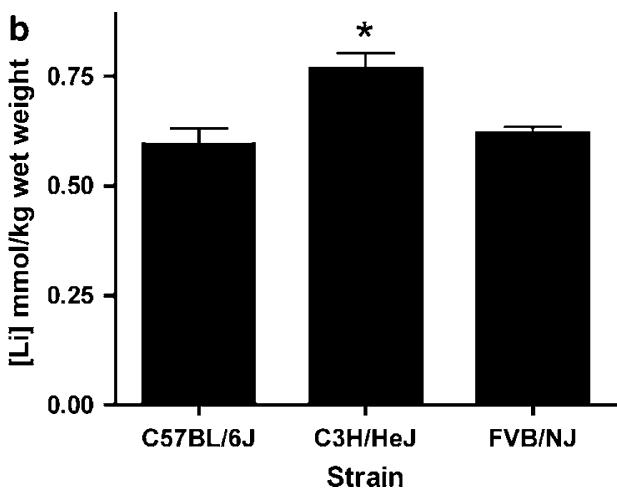

Figure 7 Serum and brain lithium levels following 4 weeks of lithium carbonate administration. (a) Serum and (b) brain lithium levels were determined for the three strains (C57BL/6), C3H/HeJ, FVB/NJ) utilized in the 4-week lithium carbonate experiments. *p 0.05 compared to the two other groups, Tukey post hoc test (6 mice per group).

After 4 weeks of treatment, mice received $d$-amphetamine in a procedure identical to the acute experiments. Activity graphs suggested a pattern similar to that observed in the acute administration studies (Figure 8). This was confirmed by statistical analysis of total distance moved. In C57BL/6J mice, there was a significant effect of both $d$-amphetamine $(\mathrm{F}(1,30)=10.76, \quad p=0.003)$, and lithium carbonate $(\mathrm{F}(1,30)=4.73, p=0.038)$, with no significant interaction $(\mathrm{F}(1,30)=2.04, p=0.16$ ) (Figure 8). In $\mathrm{C} 3 \mathrm{H} / \mathrm{HeJ}$ mice, there was a significant effect of both $d$-amphetamine $(\mathrm{F}(1,20)=11.72, \quad p<0.001) \quad$ and lithium carbonate $(\mathrm{F}(1,20)=21.57, p<0.001)$, and no significant interaction $(\mathrm{F}(1,20)=3.43, p=0.079)$ (Figure 8). In $\mathrm{FVB} / \mathrm{NJ}$ mice, there was a significant effect of $d$-amphetamine $(\mathrm{F}(1,20)=11.72, p=0.003)$, no significant effect of lithium carbonate, $\mathrm{F}(1,20)=1.95, p=\mathrm{NS}$; and no significant interaction $(\mathrm{F}(1,20)=0.035, p=\mathrm{NS})$ (Figure 8$)$. As with the acute experiments, Tukey post hoc test was used to compare control/saline with lithium carbonate/saline-treated mice, and control $/ d$-amphetamine with lithium carbonate/damphetamine-treated mice within each strain. There was no significant effect of lithium carbonate on baseline activity in C57BL/6J, FVB/NJ, or $\mathrm{C} 3 \mathrm{H} / \mathrm{HeJ}$ mice. Four weeks of lithium carbonate treatment significantly decreased $d$-amphetamine-induced hyperlocomotion in C57BL/6J $(p<0.05)$ and significantly increased $d$-amphetamine-induced hyperlocomotion in $\mathrm{C} 3 \mathrm{H} / \mathrm{HeJ}$ mice $(p<0.001)$, without significantly affecting $d$-amphetamine-induced hyperlocomotion in FVB/NJ mice (Figure 8). Thus, these experiments show that long-term administration of lithium carbonate recapitulates the actions of the acute $\mathrm{LiCl}$ administration on $d$-amphetamine hyperlocomotion.

\section{DISCUSSION}

These results describe mouse strain variation in lithium attenuation of $d$-amphetamine-induced hyperlocomotion. All strains, with the exception of A/J mice, had significantly increased locomotion following administration of $d$ amphetamine. A single administration of $\mathrm{LiCl}$ had no significant effect on baseline activity at the dosages utilized (see discussion below). However, this dose of $\mathrm{LiCl}$ attenuated $d$-amphetamine-induced hyperlocomotion in C57BL/6J, C57BL/6Tac, Black Swiss, and CBA/J mice, whereas it did not significantly attenuate $d$-amphetamineinduced hyperlocomotion in CD-1, DBA/2J, 129S6/SvEv, $\mathrm{FVB} / \mathrm{NJ}, \mathrm{SWR} / \mathrm{J}$, and NIH Swiss mice. In C3H/HeJ mice, LiCl administration increased $d$-amphetamine hyperlocomotion. Brain lithium levels $45 \mathrm{~min}$ after $\mathrm{LiCl}$ administration were not correlated with the effects of $\mathrm{LiCl}$ on $d$-amphetamine hyperlocomotion, indicating that it is not the concentration of lithium that causes the behavioral change, but rather how the brains of these mice respond to lithium. Further, the results cannot be attributed to the dose of $d$-amphetamine or LiCl, as changing the dose of either did not result in attenuation of hyperlocomotion in the non-responsive strain, FVB/NJ. Lithium carbonate administration for 4 weeks before administration of $d$-amphetamine, in a subset of strains, produced the same effects on hyperlocomotion as acute administration in C57BL/6J (decrease), $\mathrm{C} 3 \mathrm{H} / \mathrm{HeJ}$ (increase), and $\mathrm{FVB} / \mathrm{NJ}$ (no change). Some limitations to our study include the fact that lithium has a narrow dose range complicated by toxicity at higher concentrations, and the fact that lithium acts acutely in our model, but requires chronic use for its full clinical effects in humans. Further, the utility of this model in predicting the actions of other mood-stabilizing medications is unclear. Below we discuss each of these limitations in turn.

Clinically, lithium has a narrow dose range (0.5-1.2 mM), below which the medication is largely ineffective and above which severe toxic effects are observed. This narrow dose range in humans is consistent with our experience with mice, where at $50 \mathrm{mg} / \mathrm{kg}$ there was no significant effect of lithium to attenuate $d$-amphetamine-induced hyperlocomotion in C57/BL6J mice (Figure 1), but at $300 \mathrm{mg} / \mathrm{kg}$ there is a significant decrease in general open field activity, as well as other signs of toxicity, including diarrhea and slowed reaction times (unpublished observations). We thus chose a dose of $100 \mathrm{mg} / \mathrm{kg} \mathrm{LiCl}$ for our screen of 12 mouse strains. One possible explanation for our findings is that mouse strains that are responsive to lithium in this model are more sensitive to the toxic effects of lithium than lithium nonresponsive strains. A few observations argue against a role for lithium's toxic effects in the modulation of the behavioral differences we found. Whereas there is a clear dose-response relationship between the dose of $\mathrm{LiCl}$ administered to C57/BL6J mice and a decrease of locomotion in this strain (Figures 1 and 6), no such relationship exists in a representative non-responsive strain, FVB/NJ 

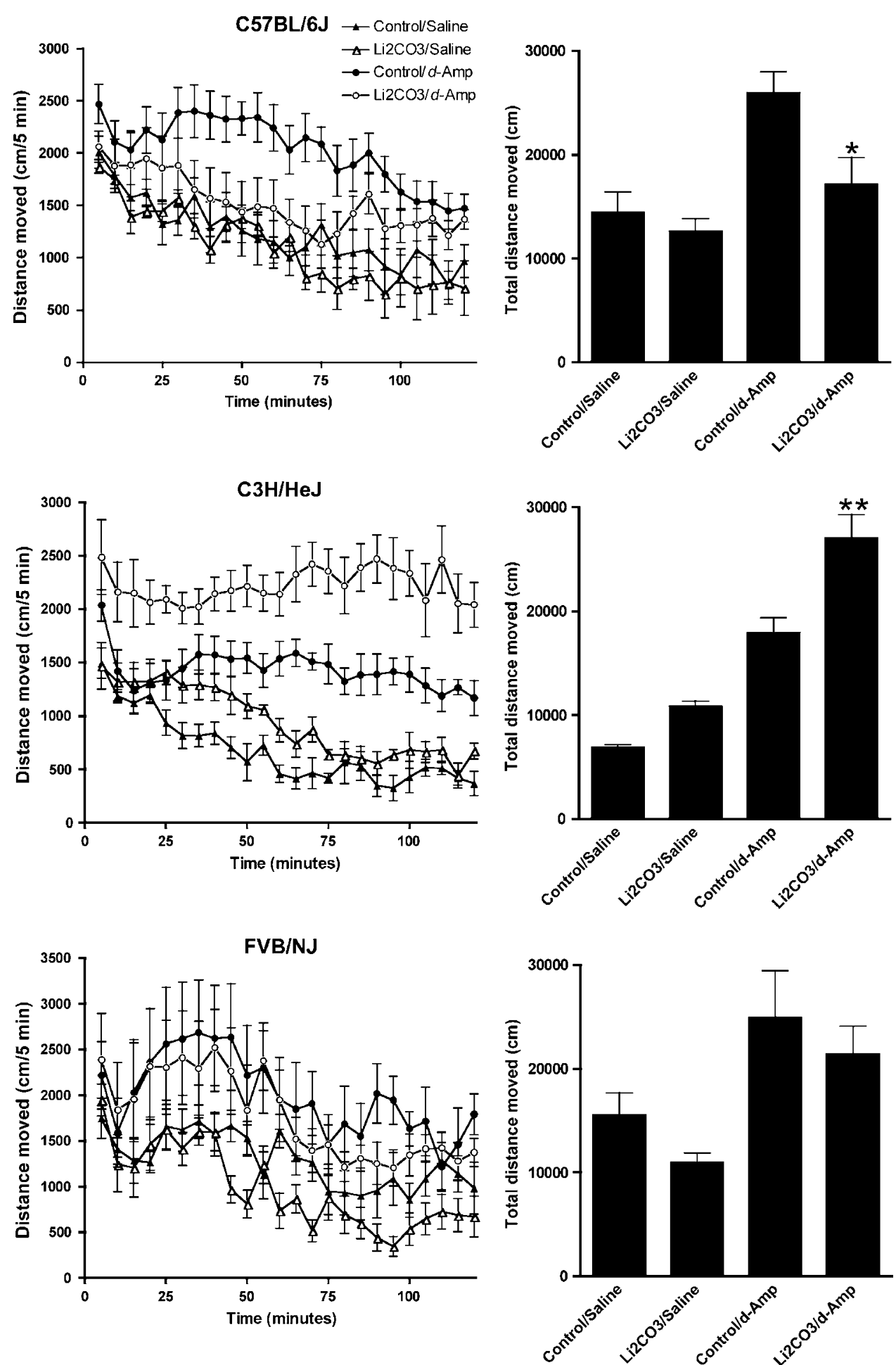

Figure 8 Effects of 4 weeks of lithium carbonate administration on $d$-amphetamine hyperlocomotion. Mice received either ( 1 ) control chow and no $d$ amphetamine (Control/Saline), (2) lithium carbonate chow and no d-amphetamine ( $\mathrm{Li}_{2} \mathrm{CO}_{3} / \mathrm{Saline}$ ), (3) control chow and d-amphetamine (Control/d-Amp), or (4) lithium carbonate chow and d-amphetamine $\left(\mathrm{Li}_{2} \mathrm{CO}_{3} / \mathrm{d}-\mathrm{Amp}\right)$. Graphs on the left show distance moved ( $\left.\mathrm{cm}\right)$ during 5-min intervals. Graphs on the right show total distance moved $(\mathrm{cm})$ during 30-90 min for the same group of mice shown on the left. Top: C57BL/6) mice; middle: C3H/HeJ mice; bottom: FVB/NJ mice. * $p<0.05$; ** $p<0.0$ I comparing control chow/d-amphetamine and lithium carbonate chow/d-amphetamine groups, Tukey post hoc test (6-I I mice per group).

(Figure 6). Importantly, similar to C57BL/6J mice, we have observed signs of toxicity in $\mathrm{FVB} / \mathrm{NJ}$ mice at a $\mathrm{LiCl}$ concentration of 200 and $300 \mathrm{mg} / \mathrm{kg}$ (unpublished observations), suggesting a similar dose range for the toxic effects of lithium in both strains. Further, overall, we did not observe any significant effect of $\mathrm{LiCl}$ to attenuate baseline locomotion for the $30-90 \mathrm{~min}$ time frame in any of the strains studied (Table 1; Figures 2 and 4). However, it is 
important to mention that during the first $30 \mathrm{~min}$ of activity, the lithium-treated mice of some strains tended to show decreased baseline locomotion (Figures 2 and 3). Because we were interested in locomotor activity unrelated to the effects of a novel environment, we determined before the experiments that we would not begin the analysis of total distance moved at time zero. Instead, we decided to begin the analysis after $30 \mathrm{~min}$, in order to eliminate effects of acclimation and exploration, as well as the delayed effects of $d$-amphetamine in certain strains, and possible acute nonspecific toxic effects of $\mathrm{LiCl}$. However, the effect of lithium on exploratory behavior in some strains may be related to our findings, as exploratory activity is largely dopamine mediated (Zhuang et al, 2001). The possibility that toxic effects of lithium are relevant to our findings is further challenged by the fact that similar strain-dependent effects of lithium to attenuate $d$-amphetamine-induced hyperlocomotion were observed following both acute and chronic administration of lithium. Toxic effects should have been more obvious following chronic administration of the drug; however, none were noted in any of the three strains studied in this experiment.

It is generally acknowledged that in patients with mood disorders, the initial therapeutic effects of lithium are only observed following many days, if not weeks, of treatment. Further, the full therapeutic effects of the drugs are often observed after months of treatment. Even though we report strain differences following 4 weeks of lithium carbonate administration at therapeutic concentrations, these effects in our model are also observed acutely. Thus, the effects of lithium on $d$-amphetamine-induced hyperlocomotion are likely best viewed as resulting from an acute initial action of the drug, rather than from the long-term plastic effects that are involved in the ultimate therapeutic effects. However, this does not suggest that our results lack importance, as evidence for the initial therapeutic action of lithium would unquestionably be a major advance. Indeed, the full effects of antidepressants, like those of lithium, are only seen after chronic administration; however, the development of these medications has proven that such an approach is worthwhile. Specifically, the development of selective serotonin reuptake inhibitors was based upon the acute mechanism of action of tricyclic antidepressants. Similarly, novel lithiummimetic drugs may not cure bipolar disorder, but they would have improved tolerability, and perhaps efficacy, as the elimination of nonspecific effects would result in a broader therapeutic window. Therefore, this model is likely to be most useful for the discovery of initial direct targets of lithium, rather than long-term, plasticity-related targets. Whereas lithium has both antidepressant and antimanic effects, clinically the attenuation of $d$-amphetamine-induced hyperlocomotion likely represents a better model for the treatment of bipolar mania. However, we cannot rule out the possibility that our model may be useful to understand both the antidepressant and antimanic effects of lithium or that the direct target of lithium in this model is relevant to the treatment of both phases of the illness. A possible mechanism to explain the direct acute effects of lithium in this model involves the attenuation of $G$ protein-mediated signal transduction and/or adenylate cyclase activity (Ebstein et al, 1978; Hamburger-Bar et al, 1986). Another possible candidate is lithium's inhibition of GSK-3
(Beaulieu et al, 2004; Klein and Melton, 1996). The use of this model with compounds specific to these and other actions of lithium can address the question of what immediate effects of lithium might underlie its attenuation of $d$-amphetamine-induced hyperlocomotion.

An important consideration is the relevance of our findings, and the sensitivity of this model, to other moodstabilizing medications. Both typical and atypical antipsychotics block dopaminergic neurotransmission, and these medications are useful for the treatment of bipolar mania. Emerging evidence also suggests that bipolar depression is also responsive to antipsychotics (Calabrese et al, 2005; Tohen et al, 2006). Therefore, this model is relevant to the study of antipsychotic medications, and dopamine itself, in the treatment of bipolar disorder. Lithium has been reported to affect the levels of synaptic dopamine in animal models; specifically, long-term administration of lithium alters dopamine levels or release, an effect that is not generally observed following short-term administration (Baptista et al, 1993; Beaulieu et al, 2004; Berggren, 1985; Corrodi et al, 1967; Dziedzicka-Wasylewska et al, 1996; Ferrie et al, 2005a, b; Friedman and Gershon, 1973; Gambarana et al, 1999). Most recently, Ferrie et al (2005a) have reported that 4 weeks of lithium administration decreases potassium-evoked dopamine release in the shell of the nucleus accumbens. These results persisted even after withdrawal of the drug for 3 days, suggesting a maintained compensatory effect on dopamine release, rather than a direct effect of lithium (Ferrie et al, 2005a). Chronic lithium administered to rodents can thus decrease the release of dopamine in brain areas relevant to the hyperlocomotion effects of $d$-amphetamine. However, the fact that these effects are generally neither observed acutely nor immediately reversed by lithium clearance implicates another mechanism in the acute effects of lithium in this model. Therefore, the effect of chronic lithium to decrease dopamine release is likely secondary to the immediate actions of the drug. Although attenuation of $d$-amphetamine-induced hyperlocomotion is an action shared by both lithium and antipsychotic medications, we have recently found that lithium has no effects on either sensitization to repeated $d$-amphetamine administration or the stereotyped behavior elicited by high doses of $d$-amphetamine, further supporting the idea that the actions of lithium on these behaviors may diverge downstream of dopamine receptors (Gould et al, submitted). It has been reported that anticonvulsant mood stabilizers, such as valproate or carbamazepine, are more active in reducing hyperlocomotion induced by a $d$-amphetamine/chlorodiazepoxide mixture than that induced by $d$-amphetamine alone (Arban et al, 2005). This effect, like that seen in our study, may be strain dependent, and warrants further investigation.

One of our goals in this study is to provide a model system for the discovery of genes that underlie the response to lithium. Our hypothesis is that homologues of the genes that control this behavior in mice may be relevant to genes underlying clinical response to lithium in humans. Among the lithium-responsive strains in our study (Black Swiss, C57BL/6J, C57BL/6Tac, and CBA/J), C57BL/6J and C57BL/ $6 \mathrm{Tac}$ are closely related, whereas the Black Swiss founders were derived from an NIH Swiss and C57BL/6N cross (www.taconic.com; www.jax.org). These strains appear to 
have no close relation to the CBA/J strain (Beck et al, 2000). To our knowledge, two previous studies have investigated mouse strain differences in lithium attenuation of $d$ amphetamine hyperlocomotion. Hamburger-Bar et al (1986) reported differences in $d$-amphetamine- $(2 \mathrm{mg} / \mathrm{kg})$ induced hyperactivity (over $30 \mathrm{~min}$, measured by midline crossings calculated every $15 \mathrm{~s}$ ) following 3 weeks of lithium chow ( $4 \mathrm{~g} \mathrm{LiCl} / \mathrm{kg}$ chow) in six mouse strains, obtained from local breeding facilities at Hadassah-Hebrew University in Israel. They concluded that in two strains $(\mathrm{C} 3 \mathrm{H}$ and $\mathrm{A})$, $d$-amphetamine stimulated activity and $\mathrm{LiCl}$ blocked this activity; in another two strains (AKR and Balb/c), $d$ amphetamine had no effect on activity; and in two other strains (C57BL and CBA/LAC), there was no $\mathrm{LiCl}$ response. Gould et al (2001) reported different sensitivities of the inbred mouse strains $\mathrm{C} 57 \mathrm{BL} / 6 \mathrm{nCrlBr}$ and $\mathrm{C} 3 \mathrm{H} / \mathrm{HenCrlBR}$ to $\mathrm{LiCl}(1-4 \mathrm{mEq} / \mathrm{kg})$ attenuation of $d$-amphetamine $(3 \mathrm{mg} / \mathrm{kg})$ hyperlocomotion. In the same study, this group evaluated the effects of lighting conditions and shape of arena on the induction and attenuation of activity. They found that $\mathrm{LiCl}$ administered $50 \mathrm{~min}$ before $d$-amphetamine, and $60 \mathrm{~min}$ before a testing period of $10 \mathrm{~min}$, prevented amphetamineinduced increases in locomotor activity in $\mathrm{C} 57 \mathrm{BL} / 6 \mathrm{nCrlBr}$ mice. They did not find an increase in locomotor activity in $\mathrm{C} 3 \mathrm{H} / \mathrm{HenCrlBR}$ mice following administration of $d$-amphetamine. An attempt to compare any findings from our study to these reports is necessarily complicated by methodological differences, and by the fact that different substrains, between which biological differences are common, were used. This difficulty emphasizes the need to standardize procedures and strains between laboratories.

The need for an improved understanding of the neurobiological antecedents, the development of novel medications, and improved animal models for bipolar disorder has recently been emphasized (Einat, 2006; Zarate et al, 2006). The action of lithium in the present model may be at the receptor or post-receptor level, and potentially includes inhibition of $\mathrm{G}$ protein-mediated signal transduction and/or GSK-3 (Beaulieu et al, 2004; Ebstein et al, 1978). Our findings provide a model by which to study the biological and genetic underpinnings of mouse strain differences in lithium attenuation of $d$-amphetamine hyperlocomotion. Future studies of genetic differences between mouse strains that are responsive and unresponsive to lithium in this model may also lead to a better understanding of the variation in responsiveness to lithium among patients with bipolar disorder.

\section{ACKNOWLEDGEMENTS}

We appreciate the assistance of $\mathrm{Dr}$ Haim Einat, $\mathrm{PhD}$, University of Minnesota Duluth, in manuscript review of David A Luckenbaugh, MA, NIMH Mood and Anxiety Program Biostatistician, in statistical analysis. The research was supported by the Intramural Research Program of the National Institute of Mental Heath, the Foundation for the National Institutes of Health (Neuroscience Research Fellowship (TDG)), the National Association for Research on Schizophrenia and Depression (Young Investigator Award to TDG), and the Stanley Research Foundation (HKM).

\section{REFERENCES}

Anand A, Verhoeff P, Seneca N, Zoghbi SS, Seibyl JP, Charney DS et al (2000). Brain SPECT imaging of amphetamine-induced dopamine release in euthymic bipolar disorder patients. $\mathrm{Am} \mathrm{J}$ Psychiatry 157: 1108-1114.

Angst J, Gamma A, Benazzi F, Ajdacic V, Eich D, Rossler W (2003). Diagnostic issues in bipolar disorder. Eur Neuropsychopharmacol 13(Suppl 2): S43-S50.

Anisman H, Wahlsten D, Kokkinidis L (1975). Effects of $d$-amphetamine and scopolamine on activity before and after shock in three mouse strains. Pharmacol Biochem Behav 3: 819-824.

Arban R, Maraia G, Brackenborough K, Winyard L, Wilson A, Gerrard P et al (2005). Evaluation of the effects of lamotrigine, valproate and carbamazepine in a rodent model of mania. Behav Brain Res 158: 123-132.

Baptista T, Teneud L, Contreras Q, Burguera JL, Burguera M, Hernandez L (1993). Effects of acute and chronic lithium treatment on amphetamine-induced dopamine increase in the nucleus accumbens and prefrontal cortex in rats as studied by microdialysis. J Neural Transm Gen Sect 94: 75-89.

Beaulieu JM, Sotnikova TD, Yao WD, Kockeritz L, Woodgett JR, Gainetdinov RR et al (2004). Lithium antagonizes dopaminedependent behaviors mediated by an AKT/glycogen synthase kinase 3 signaling cascade. Proc Natl Acad Sci USA 101: 5099-5104.

Beck JA, Lloyd S, Hafezparast M, Lennon-Pierce M, Eppig JT, Festing MF et al (2000). Genealogies of mouse inbred strains. Nat Genet 24: 23-25.

Bell EC, Willson MC, Wilman AH, Dave S, Asghar SJ, Silverstone PH (2005). Lithium and valproate attenuate dextroamphetamine-induced changes in brain activation. Hum Psychopharmacol 20: 87-96.

Berggren U (1985). Effects of chronic lithium treatment on brain monoamine metabolism and amphetamine-induced locomotor stimulation in rats. J Neural Transm 64: 239-250.

Berggren U, Tallstedt L, Ahlenius S, Engel J (1978). The effect of lithium on amphetamine-induced locomotor stimulation. Psychopharmacology (Berl) 59: 41-45.

Berridge MJ, Downes CP, Hanley MR (1989). Neural and developmental actions of lithium: a unifying hypothesis. Cell 59: 411-419.

Borison RL, Sabelli HC, Maple PJ, Havdala HS, Diamond BI (1978). Lithium prevention of amphetamine-induced 'manic' excitement and of reserpine-induced 'depression' in mice: possible role of 2-phenylethylamine. Psychopharmacology (Berl) 59: 259-262.

Calabrese JR, Keck Jr PE, Macfadden W, Minkwitz M, Ketter TA, Weisler RH et al (2005). A randomized, double-blind, placebocontrolled trial of quetiapine in the treatment of bipolar I or II depression. Am J Psychiatry 162: 1351-1360.

Corrodi H, Fuxe K, Hokfelt T, Schou M (1967). The effect of lithium on cerebral monoamine neurons. Psychopharmacologia 11: 345-353.

Cox C, Harrison-Read PE, Steinberg H, Tomkiewicz M (1971). Lithium attenuates drug-induced hyperactivity in rats. Nature 232: 336-338.

Dziedzicka-Wasylewska M, Mackowiak M, Fijat K, Wedzony K (1996). Adaptive changes in the rat dopaminergic transmission following repeated lithium administration. J Neural Transm 103: 765-776.

Ebstein RP, Reches A, Belmaker RH (1978). Lithium inhibition of the adenosine-induced increase of adenylate cyclase activity. J Pharm Pharmacol 30: 122-123.

Einat $\mathrm{H}$ (2006). Modelling facets of mania-new directions related to the notion of endophenotypes. J Psychopharmacol 20: 714-722.

Einat H, Manji HK, Belmaker RH (2003). New approaches to modeling bipolar disorder. Psychopharmacol Bull 37: 47-63. 
Ferrie L, Young AH, McQuade R (2005a). Effect of lithium and lithium withdrawal on potassium-evoked dopamine release and tyrosine hydroxylase expression in the rat. Int J Neuropsychopharmacol 1-7.

Ferrie L, Young AH, McQuade R (2005b). Effect of chronic lithium and withdrawal from chronic lithium on presynaptic dopamine function in the rat. J Psychopharmacol 19: 229-234.

Friedman E, Gershon S (1973). Effect of lithium on brain dopamine. Nature 243: 520-521.

Gambarana C, Ghiglieri O, Masi F, Scheggi S, Tagliamonte A, De Montis MG (1999). The effects of long-term administration of rubidium or lithium on reactivity to stress and on dopamine output in the nucleus accumbens in rats. Brain Res 826: 200-209.

Ghoshdastidar D, Dutta RN, Poddar MK (1989). In vivo distribution of lithium in plasma and brain. Indian J Exp Biol 27: 950-954.

Gottesman II, Gould TD (2003). The endophenotype concept in psychiatry: etymology and strategic intentions. Am J Psychiatry 160: 636-645.

Gould TD, Chen G, Manji HK (2004a). In vivo evidence in the brain for lithium inhibition of glycogen synthase kinase-3. Neuropsychopharmacology 29: 32-38.

Gould TD, Einat H, O’Donnell KC, Picchini AM, Schloesser RJ, Manji HK (submitted). Beta-catenin overexpression in the mouse brain phenocopies lithium-sensitive behaviors.

Gould TD, Gottesman II (2006). Psychiatric endophenotypes and the development of valid animal models. Genes Brain Behav 5: 113-119.

Gould TD, Gray NA, Manji HK (2003). Effects of a glycogen synthase kinase- 3 inhibitor, lithium, in adenomatous polyposis coli mutant mice. Pharmacol Res 48: 49-53.

Gould TD, Quiroz JA, Singh J, Zarate CA, Manji HK (2004b). Emerging experimental therapeutics for bipolar disorder: insights from the molecular and cellular actions of current mood stabilizers. Mol Psychiatry 9: 734-755.

Gould TJ, Keith RA, Bhat RV (2001). Differential sensitivity to lithium's reversal of amphetamine-induced open-field activity in two inbred strains of mice. Behav Brain Res 118: 95-105.

Hamburger-Bar R, Robert M, Newman M, Belmaker RH (1986). Interstrain correlation between behavioural effects of lithium and effects on cortical cyclic AMP. Pharmacol Biochem Behav 24: 9-13.

Hasler G, Drevets WC, Gould TD, Gottesman II, Manji HK (2006). Toward constructing an endophenotype strategy for bipolar disorders. Biol Psychiatry 60: 93-105.

Huey LY, Janowsky DS, Judd LL, Abrams A, Parker D, Clopton P (1981). Effects of lithium carbonate on methylphenidate-induced mood, behavior, and cognitive processes. Psychopharmacology (Berlin) 73: 161-164.
Kitahama K, Valatx JL (1979). Strain differences in amphetamine sensitivity in mice. I. A diallel analysis of open field activity. Psychopharmacology (Berlin) 66: 189-194.

Klein PS, Melton DA (1996). A molecular mechanism for the effect of lithium on development. Proc Natl Acad Sci USA 93: $8455-8459$.

Mamelak M (1978). An amphetamine model of manic-depressive illness. Int Pharmacopsychiatry 13: 193-208.

Morrison Jr JM, Pritchard HD, Braude MC, D'Aguanno W (1971). Plasma and brain lithium levels after lithium carbonate and lithium chloride administration by different routes in rats. Proc Soc Exp Biol Med 137: 889-892.

Mukherjee BP, Bailey PT, Pradhan SN (1976). Temporal and regional differences in brain concentrations of lithium in rats. Psychopharmacology (Berl) 48: 119-121.

Murphy DL, Brodie HK, Goodwin FK, Bunney Jr WE (1971). Regular induction of hypomania by L-dopa in 'bipolar' manicdepressive patients. Nature 229: 135-136.

Peet M, Peters S (1995). Drug-induced mania. Drug Saf 12: 146-153.

Schou M (2001). Lithium treatment at 52. J Affect Disord 67: 21-32.

Silverstone PH, Pukhovsky A, Rotzinger S (1998). Lithium does not attenuate the effects of $\mathrm{D}$-amphetamine in healthy volunteers. Psychiatry Res 79: 219-226.

Tohen M, Calabrese JR, Sachs GS, Banov MD, Detke HC, Risser R et al (2006). Randomized, placebo-controlled trial of olanzapine as maintenance therapy in patients with bipolar I disorder responding to acute treatment with olanzapine. Am J Psychiatry 163: 247-256.

van Kammen DP, Docherty JP, Marder SR, Rosenblatt JE, Bunney Jr WE (1985). Lithium attenuates the activation-euphoria but not the psychosis induced by $d$-amphetamine in schizophrenia. Psychopharmacology (Berl) 87: 111-115.

Van Kammen DP, Murphy DL (1975). Attenuation of the euphoriant and activating effects of $d$ - and $l$-amphetamine by lithium carbonate treatment. Psychopharmacologia 44: 215-224.

Willson MC, Bell EC, Dave S, Asghar SJ, McGrath BM, Silverstone PH (2005). Valproate attenuates dextroamphetamine-induced subjective changes more than lithium. Eur Neuropsychopharmacol 15: 633-639.

Zarate Jr CA, Singh J, Manji HK (2006). Cellular plasticity cascades: targets for the development of novel therapeutics for bipolar disorder. Biol Psychiatry 59: 1006-1020.

Zhuang X, Oosting RS, Jones SR, Gainetdinov RR, Miller GW, Caron MG et al (2001). Hyperactivity and impaired response habituation in hyperdopaminergic mice. Proc Natl Acad Sci USA 98: 1982-1987. 